\title{
Dynamics of gender-based violence among the Tivs of North Central Nigeria
}

\author{
Clifford Odimegwu \\ Program in Demography and Population Studies \\ University of the Witwatersrand, Johannesburg, South Africa \\ Clifford.Odimegwu@wits.ac.za \\ Christian N. Okemgbo \\ 1930 George Washington Way, Richland, WA \\ Rosemary Ayila \\ Research Center for Health and Gender Equity, Gboko, Nigeria.
}

\section{Abstract}

Gender-based violence has been noted as a major international public health and human right issue. Still relatively little is known about its frequency, sub-cultural variations and correlates in Nigeria. Data from a cross-sectional sample of women in the North Central Region of Nigeria were used to examine women's experience and perception of gender-based violence. The types and levels of gender-based violence were measured and logistic regression was performed to identify critical significant factors affecting different types of gender-based violence. This was done by analyzing the association between socioeconomic, cultural and demographic variables and types of gender-based violence identified in the study.

While there is a high prevalence of gender-based violence in terms of wife battery and marital sexual rape, their incidence is low. There is social approval for intimate partner violence while respondents did not agree that sexual rape occurs in marriage. Attitudes to gender-based violence are supportive as most participant-respondents see the tradition of wife battery as a demonstration of love. Most respondents would not report any experience of gender-based violence to the law enforcement agencies and the public. Women who have suffered intimate partner violence are more likely to have suffered rape and psychological abuse. There is statistical difference in social-health consequences reported by abused and non-abused women. There is no consistent association between socioeconomic and demographic variables and types of gender-based violence. Genderbased violence interventions should focus on its social-health consequences instead of how to change men. A significant progress would be made if communities and individuals are aware of the social, human right and reproductive health consequences of forms of gender-based violence.

Keywords: Gender, violence, sexual, reproductive health, human rights 


\section{Résumé}

La violence basée sur le genre est considérée comme un problème majeur international de santé publique et de droit de l'homme. Cependant il y a relativement peu de connaissance sur sa fréquence, ses variations culturelles et ses corrélats au Nigeria. Des données d'un échantillon de femmes de la North Central Region du Nigeria ont été utilisées pour examiner les expériences et perceptions des femmes de la violence basée sur le genre. Les types et niveaux de la violence basée sur le genre ont été mesurés et une régression logistique exécutée pour identifier les facteurs déterminants significatifs qui affectent les différents types de violence basée sur le genre. Ceci a été fait en analysant l'association entre les variables socioéconomiques, culturelles et démographiques et les types de violence basée sur le genre identifiés dans l'étude.

Bien qu'il y ait une forte prévalence de la violence basée sur le genre en termes de femmes mariées battues et de viol sexuel conjugal, leur incidence est faible. II y a approbation sociale pour la violence entre partenaires intimes pendant que les enquêtées ne sont pas d'accord que le viol sexuel se produise dans le mariage. Les attitudes envers la violence basée sur le genre sont celles de soutien, la plupart des répondants à l'enquête participative considérant la tradition de femme battue comme une démonstration d'amour. La plupart des enquêtées ne déclareraient pas des expériences de violence aux agences chargées de mettre en vigueur la loi et le public. Les femmes qui ont souffert de violence de leur partenaire intime ont probablement plus souffert de viol sexuel et d'abus psychologique. Il y a une différence statistique entre les conséquences sociales et sanitaires rapportées par les femmes abusées et de celles qui ne sont pas abusées. II n'y aucune association cohérente entre les variables socioéconomiques et démographiques et les types de violence basée sur le genre. Les interventions sur la violence basée sur le genre devraient être concentrées sur les conséquences sociales et sanitaires au lieu de comment changer les hommes. Du progrès significatif serait réalisé si les communautés et les individus prennent conscience des conséquences sociales, sur les droits de l'homme et la santé de la reproduction de toutes les formes de violence basée sur le genre.

Mots clé : Genre, violence, santé de la reproduction, droit de l'homme

\section{Introduction}

Scientific literature has provided numerous examples of violence perpetrated upon the dependent and the weak within the family. In most societies, it has been institutionalized as the right of the powerful while in others it has been the result of a variety of personal and environmental causes. In recognition of this, many theoreticians and researchers have been interested in raising public awareness regarding vio- lence against women (Heise et al. 1994a: Heise et al. 1994b; Okemgbo et al. 2002: Haj-Yahia 2000; Beijing Platform 1995). The UN Declaration on the Elimination of Violence Against Women (DEVAW) has defined violence against women as all gender-based violent acts occurring in both the family and public which result in physical, sexual or psychological harm or suffering to women. It is any act of force or coercion with intent to perpetuate or pro- 
mote hierarchical gender relationships (Albert, 1994: Odimegwu,2000; Beijing Platform Platform 1995). It is variously called 'domestic violence' or 'family violence'. It may be psychological or mental violence, which can consist of repeated verbal abuse, harassment, confinement and deprivation of physical, financial and personal resources (Afkami et al. 1998; Odimegwu 2000, Blanc et al. 1996). Since United Nations agencies drew attention to the problem, studies on gender-based violence have been conducted in various countries. African studies point to an increasing trend in violence against women (Raikes 1990; Coker and Richter 1998; Odimegwu and Okemgbo, 2003).

In Nigeria interest in studying and addressing the problem of genderbased violence is emerging as researchers are beginning to document the prevalence and correlates of violence against women (Sogbetun and Osoba, 1977; Kisseka and Otesanya, 1988; Odunjirin 1993; Odimegwu, 1998; OAU, 1998; Okemgbo et al. 2002). These emerging attempts at investigation of violence against women in Nigeria have not categorized the various patterns of this aspect of genderbased violence, nor have they being able to situate the timing of the aspects of violence. More importantly none of these studies has investigated the correlates of different forms of genderbased violence. This is the gap this present article intends to fill. While these studies and others indicate that violence against women occurs against women of all ages and from all socioeconomic variables, the need still exists to further explore the impact of socioe- conomic, demographic and cultural factors on the various forms of violence against women (Heise et al. 1994a; 1994b).

\section{Theoretical, conceptual and methodological Issues in the study of gender-based violence}

Gender-based violence has been explained using various theoretical formulations. One of these sees genderbased violence as evidence of individual psychological problems of perpetrators, victims' characteristics and environmental circumstances. The causes are eradicable individual problems, which are generally psychological or social in origin such as stress, poverty, unemployment or substance abuse (Connors, 1989; Hoffman et al. 1994). This idea can be faulted on the ground that it sees the problem of violence against women as an individual and private affair. Its causal explanation is weak since violence against women cuts across all socio-economic, racial and class groupings.

The cause of family violence has also been postulated to lie in the structure of the society, which is both a product and a reinforcement of the unequal distribution of power between men and women and between adult and child. At the core of this theory is the unequal balance of power between men and women that is institutionalized within the patriarchal family. Violence against women is seen in a social context tolerating the subordination of women. It is explained as a structural problem rather than an isolated case within individual relationships because the violence is located in the frame- 
work of cultural, socio-economic and political power relations with factors that allow violence to occur. Patriarchal values support female inferiority and are transmitted to younger generations with family violence tolerated as a male right to control those who are dependent (Coker and Richter, 1998) . Most of these theories on the structure of family violence tend to agree that when a society tolerates physical violence as a mechanism for conflict resolution, and when it accepts male superiority and authority in decision-making within the home, it provides the ideal blueprint for violence against women (Carrillo, 1992; Heise et al. 1994b; Connors, 1989).

These theories locate the family as the unit of abuse because it is above reproof by external interference. Cultural values, which in most cases are patriarchal values, stress family autonomy, making others loathe the intervention in violent situations. Patriarchal values support women's inferiority within intimate relations, with the male usually the dominant family member holding the most decision making power. The family's younger generations are socialized into this dominant male behavior and, for the female group, to accept their low position as the status quo. Women's low status then becomes institutionalized within the structure of the family and domestic violence is tolerated as a male right to control those who are considered inferior, the women. The society reinforces family structure and women's position within it, tacitly accepting domestic violence as typical behaviour. It also supports the low status of women by either not valuing or undervaluing their work. Thus it is concluded that this keeps women vulnerable to violence by maintaining their social and economic dependence on men (Heise et al. 1994b). In Tiv society, traditional norms and beliefs have dominated family relationships and prevented societal recognition of or intervention in all matters of family violence .

There are a number of conceptual and methodological flaws in the study of gender-based violence. One, there is the problem of under-estimation due to underreporting, as many battered women may choose not to expose their experiences because these matters are seen as a purely private family affair. Revealing such experience, they may feel embarrassed, ashamed or guilty about the situation. They may be apprehensive or frightened that their husbands or partners will take revenge if they find out or they may think that the incident is trivial and a normal thing (Kim and Cho, 1992; Koenig et al. 1999; Koenig et al. 2003). They may also have forgotten what has happened and hence could not report accurately. The reported results are diverse such that they are difficult to compare. There are different research populations, instruments for measurement (eg exclusive use of Conflict Tactical Scales versus use of one question or a few questions about violence; data collection methods (qualitative or quantitative), varying sample size, nature of sample, etc. These differences, no doubt, constitute potential causes for discrepancies in reported prevalence rates of violence against women. Finally, most of the surveys have focused primarily on measuring physical violence against women, and few have addressed other forms of women abuse such as psychological, 
economic and sexual abuse. Most of the studies outside North America used scales developed for the Western Societies. These instruments were not culturally or socially adapted to the sociocultural contexts of the societies in which the studies were conducted (Haj-Yahia 2000), hence their application to developing countries is questionable.

Although the various studies reported may generate considerable knowledge about incidence and prevalence of wife abuse and battering in different societies, the findings still cannot be generalized to other areas. Culturespecific studies are needed in a multiethnic country like Nigeria. The present paper documents a community-based survey on the incidence, prevalence, patterns and consequences of domestic violence in Tiv society of the North Central Region of Nigeria. The study is one of the efforts at documenting the level of gender-based violence in Nigeria with a view to designing culture-specific programs to address the associated problems.

\section{Geographical background}

This study was done among the Tivspeaking people of Benue State, Nigeria. The Tivs live in the Gboko area of Benue State in the North Central Region of Nigeria. The area is located on latitude $6^{\circ} 30^{\prime}$ North and $8^{\circ} 10^{\prime}$ in the East They are the predominant ethnic group in the State, constituting more than 768,000 inhabitants in the area (NPC, 1991). It is divided into a number of component local council areas while Gboko is the traditional headquarters of the Tiv-speaking tribe of Nigeria. It is also the most urbanized of all the Tiv-dominated areas. A tradi- tional ruler who is responsible to the Traditional Council governs each district. These are both answerable to the Ter Gboko, the chairman of Local Government Traditional Council who in turn is answerable to the paramount traditional ruler by name Tor Tiv - the lion of Tiv. The traditional council in turn is responsible to the paramount traditional ruler known as Tor Tiv. The Tiv traditional institution is interconnected and interdependent. The inhabitants are predominantly farmers. There are a number of educational and health institutions in the area.

The people of the area are predominantly farmers producing cash crops such as rice, yam, fruits, etc. Politically, until the last century, power and authority structures in Tiv society remained decentralized with the various compound heads arbitrating in disputes among the various family units. Although the Tiv have been exposed to various forms of modernizing influences, they have largely retained and jealously guarded their original lifestyles against any form of adulteration. Though they have a distinct cultural lifestyle, they have a pragmatic worldview of a well-ordered community who subject themselves to hard work and respect for societal norms and values of which the elders are the custodians (Tseror, 1992; Benue State of Nigeria 1996).

\section{Family structure and role relationship}

Family structures and role relationships among the Tivs of Nigeria are clearly defined. There is a group orientation, which fosters dependency, male supremacy and female subordination, and age-associated status. The family in 
Tiv is hierarchical, patriarchal and patrilineal. In the family structure, ideologically, the female is expected to be dependent throughout her life. Authority and respect for elders are paramount, and the family unit controls members in all areas of their lives. Among the Tiv, males are valued more than females hence the strong preference for male children. Couples go to extreme lengths to have male children who would inherit the family property while women would want male children which will guarantee them status in the married family. Men are the heads of the households, primary wage earners (in some cases), decision-makers and disciplinarians. A male child, especially the eldest male, grows up with the knowledge that he inherits the headship upon the death of his father with all the responsibilities. $\mathrm{He}$ is expected to model his behaviour after that of his father. As children, they are groomed to move into and contribute to the well being of the husband's family. A good child is seen as following in the father's footsteps while a mother is to be blamed when a child misbehaves. Women in the family are subordinate and serve as caretakers of the home while the men go out to look for resources for the upkeep of the family (Tseror, 1992).

\section{Data collection and analysis}

Permission to conduct the survey was obtained earlier through the office of the Tor Tiv - the paramount traditional ruler in the area. This traditional position is more powerful and more respected than political institutions in the state. The Tor Tiv informed his district heads of our visit and asked them to mobilize the communities for the survey. Field workers, graduates of social and nursing sciences, were recruited. These were indigenes of the area that understand the culture and language. There were ten field workers - five men and five women. These interviewers were trained for a week on the principles and methods of interviewing, the objectives of the survey and how to obtain informed consent from the potential respondents.

The survey population was drawn from the Gboko and Gwer areas of Benue State. Gboko town was the urban site while Gwer was chosen as the rural site. The urban area was divided into eight enumeration areas for the purpose of sampling. By random sampling we selected four enumeration areas. In each enumeration areas, we stratified between the elites zone, which is the government reservation area, and the migrants' zone, which constitute the low class area. The households in these areas were numbered serially. Systematic random sampling was used to select a household in every three households until we arrived at the estimated sample size in the urban area. In the rural areas, households were randomly selected. The rural areas are ethnically homogenous hence we did not stratify the areas. In the study the household was the primary sampling unit. In each household chosen, we interviewed an adult female. A total of 650 women were interviewed from the two communities but after editing the questionnaires, we have 648 usable forms for analysis.

Focus group discussions, in-depth interviews and key informants complemented the questionnaire. The indepth interviews were semi-structured 
and focused on the perceptions of and attitudes to gender-based violence. There were ten in-depth interviews of women who have been abused by their partners. There were also five key informants drawn from the communities. These are mainly community opinion leaders who were asked to comment on the incidence, prevalence, causes and consequences and perception of gender violence in the area. Their knowledge of reproductive health consequences of gender violence was assessed. There were six focus group discussions conducted. The focus group discussions were homogenous in terms of age, education and occupation. Based on the qualitative data, the survey instrument was refined and finally developed. Questions regarding women's experiences with violence and other forms of gender-based victimization including forced sexual intercourse were asked. The women's awareness and perception of reproductive health and rights, and attitudes to gender stereotypes were also assessed.

\section{Measures of gender-based violence}

Because violence against women is regarded as a private family affair which respondents do not want to recount, we framed a question to enable us introduce the subject of study. The question acknowledged that misunderstandings do occur in relationships and that partners use different means to resolve such conflicts. The respondents were given a list of things, which couples do when there is a misunderstanding. Then they were asked to indicate whichever one applied to them. After this introductory question, the main questions were asked. Rape was defined as a forceful sexual intercourse without the victim's consent. The questions were framed thus: "Have you been forced to have sexual intercourse against your will by anybody?" If yes, by whom? How old were you when you were first forced to lie with somebody against your will? Was it the first time you have sex?" To examine the current level of rape, we asked the question: "Within the last 12 months, has anyone forced you to have sex?" Further question was asked whether any of the female children of the respondent had reported experience of rape. Marital rape was also measured. Female respondents were asked whether they have had sex with their partners against their will. Reasons why they engaged in sexual intercourse with their partners after their initial refusal was also sought.

Two aspects of physical assault were measured. The lifetime physical assault commonly found in literature was measured by asking the questions: (I) Has anyone close to you ever hit, slapped, kicked or tried to hurt you physically? (2) If yes, who did that? Have you ever been beaten by your spouse or intimate partner? (3) How often? Did this ever occur when you were pregnant? Current physical violence or incidence rate was measured by asking the questions: "Were you ever beaten by your partner in the past 12 months? Within the last year, has anyone forced you to have sexual relations with him against your will?" Psychological abuse was also measured by asking the question " Have you felt belittled or insulted by your spouse?"

For the multivariate analysis, we used logistic regression, an approach 
that is functionally appropriate for the analysis of dichotomous variables. There are four dependent variables: lifetime physical violence; intimate partner violence, psychological abuse, forced sexual intercourse and current intimate partner violence. Each of these variables was dichotomized to make them compliant with a logistic regression model. Perception and attitudinal studies of this nature require the use of qualitative methods of data collection. However the use of statistics in this report is to quantify the magnitude of the problem of gender-based violence in various forms while the context of the problem of violence were explained using the qualitative data from focus group discussions, in-depth interviews and key informants interviews.

\section{Results}

Profile of respondents

More than half of the women were from the urban areas while $43.3 \%$ came from the rural sections. Slightly more than one-third were aged 15-24 and 25-34 years. More than one-third had secondary education and majority was in marital union. Petty trading, farming and housewife were the main occupations reported. On the average, each of the women had 4.3 children ever born while about 3.7 were alive. Each household has a mean family size of ten persons. The characteristics compare fairly with the Nigeria demographic and health survey report of 1999 as far as the area is concerned. (Table excluded).

Table I Distribution of respondents by the extent of agreement with reproductive rights and gender role ideologies

\begin{tabular}{|c|c|c|}
\hline Perceptions of reproductive rights & $\%$ Agreed & \% Disagreed \\
\hline $\begin{array}{l}\text { A woman has right to decide whether and } \\
\text { when to have children }\end{array}$ & 31.8 & 68.2 \\
\hline $\begin{array}{l}\text { Right to family planning availability and } \\
\text { accessibility }\end{array}$ & 15.6 & 84.4 \\
\hline Right to be equal with men & 24.2 & 75.8 \\
\hline Right to decide the number of children to have & 29.8 & 70.2 \\
\hline Right to abortion & 36.8 & 63.2 \\
\hline Right to determine when to have sex & 42.9 & 57.1 \\
\hline \multicolumn{3}{|l|}{ Perceptions of sexual ideologies } \\
\hline Unmarried girl should not have sex & 86.8 & 13.2 \\
\hline Male adolescents need not be virgins & 19.0 & 81.0 \\
\hline A boy who does not have sex is not a man & 15.3 & 84.7 \\
\hline \multicolumn{3}{|l|}{ Perceptions of gender role ideologies } \\
\hline Women should have equal rights with men & 19.4 & 80.6 \\
\hline Men are more logical than women & 80.5 & 19.5 \\
\hline Men should not display emotions & 66.8 & 33.2 \\
\hline Husband should not help in domestic chores & 68.0 & 32.0 \\
\hline
\end{tabular}


Necessary for husband to beet wife

Woman's place is in the kitchen

Men should have final say in the home

Perception of reproductive rights, sexuality and gender role ideologies

There is a noticeable low percentage of agreements with reproductive rights of women. Only about one-third agreed that a woman has right to decide the timing of childbearing. More than twothird do not agree that women should have right to decide when to have children, or have right to abortion while 57 percent disagreed that a woman should have right to determine when she will have sex with her partner. One-third agreed that a woman should have right to decide whether or when to have children, $47 \%$ agreed that women should have right to use family planning methods and four out of every ten agreed that women should have right to determine time for sex.

In terms of sexuality ideologies, majority of the women [86.8\%] agreed that sexual activities should be the prerogative of men, adult and adolescent men. The women generally support gender role ideologies. About eight in every ten disagreed that women should have equal rights with men while similar number believe that men are more logical and rational than women. Almost all of the women agreed that men should have final say in the home.

More than two-third of the women agreed that a wife should not expect 'her husband to help in domestic chores', while four out of ten women agreed that it is often necessary for a husband to beat the wife. Almost all, 94\% agreed that the husband should have
46.5

53.5

66.2

33.8

94. 1

5.9

final say on family matters. More than half agreed that a married woman must submit to her husband's authority at all times irrespective of any inconvenience to her. There is a clear-cut support for gender role ideologies by the women. This is a reflection of the tradition that has come to be accepted as normal. According to one of the respondents,

"That is what our parents told us" (30-year-old female informant)

Another respondent said that it is part of the culture and there is nothing that can be done to change it. The participants further opined that they were brought up to believe that domestic work is for women. In fact it is a yardstick for measuring whether a woman is good or bad. These patterns of responses raise the issue of the socialization process of the Tiv community. These women have been made to believe in gender inequity and the apparent difficulty and unwillingness to challenge it. It is regarded as a cultural and religious phenomenon that cannot be changed (Table excluded).

Prevalence of gender-based violence

Questions on prevalence and incidence of gender-based violence were asked. Table 2 shows the reported levels. 
Table 2 Percentage distribution of different types of violence against women, Tivland, Benue State, Nigeria

\begin{tabular}{lcc}
\hline \multicolumn{1}{l}{ Type of violence } & Frequency & Percentage \\
\hline Lifetime physical violence & 431 & 66.5 \\
Lifetime intimate partner violence & 492 & 75.9 \\
Intimate partner violence in previous I2 months & 106 & 16.4 \\
Rape & 136 & 21 \\
Marital rape & 110 & 17 \\
Adolescent rape & 123 & 19 \\
Rape and Assault & 34 & 5.3 \\
Lifetime psychological abuse & 430 & 66.4 \\
Previous I2 months psychological abuse & 448 & 69.1
\end{tabular}

More than two-thirds of the women reported having been physically assaulted in their lifetime (not necessarily by their partners) and seventy six percent of them reported their intimate partners (spouses) have assaulted them while the frequency of abuse is $1-2$ times per year. One-fifth of the women reported that they have been battered about 3-4 times per year. About onethird of the abused women (33\%) were beaten when they were pregnant, $20 \%$ took steps to protect themselves and $22 \%$ needed medical attention after sustaining injuries, an indication of the health consequences of violence against women. The current level of intimate partner violence is 16 percent. About two-thirds reported psychological abuse in their lifetime and in the twelve months preceding the survey.

The high prevalence of wife abuse or intimate partner abuse is also supported by the discussants in our focus group discussions. In one of the sessions for middle aged women in the rural area of the survey site, the women stated:
"There are many punishments our husbands give to us. They beat us. Refuse to buy clothes for us ... refuse to help us in the farm."

"women who are stubborn and do not bend down to respect their husbands are beaten ..."

"A woman who wants to escape beating by her husband should learn to obey him all the times ..." (FGD, rural, less educated women aged 30-39)

A participant in one of the focus group sessions reported recent physical violence in the neighborhood thus:

"There is an incident that took place three days ago. A woman was coming from the market. Her husband met her on the road and gave her serious beating and even tore her underwears and her clothes ... Few days ago a neighbor of mine beat his wife with about six bundles of broom sticks until all the 
sticks cut into pieces."

In this community, abused women do not report to the law enforcement agencies because,

"You don't report family matters to the police or take it to the outsiders; that will mean washing your dirty linen in the public. Even if you go the police they will tell you to go back and settle the matter with your husband ... the whole community will be against you and call you names. If you report to your parents, they will advise you to go and reconcile with him. No matter what you tell them or how horrible the abuse may be you will still be advised to go back, at least for the sake of your children and family integrity ..." (FGD, 20-29 year old women, secondary educated).

However in most serious cases, especially when life of the victim is threatened, the law enforcement agencies would be involved but respondents claimed that somewhere along the line the community will intervene to mediate in the matter.

In terms of forced sexual intercourse, $21 \%$ of the women reported they have been raped, and about one quarter were raped before their 15th birthday. The major rape perpetrators were the male friends or acquaintances and $17 \%$ claimed their husbands had sex with them against their will. Though there are indications of forced sex in marital homes, the Tivs of Nigeria do not regard it as 'rape' because they believe that with the traditional dowry paid for a woman, the husband has unhindered access to her any time any day. The question commonly asked in most of our focus group discussions is "Can a husband be said to rape the wife?" Thus the Tiv society does not recognize the existence of marital rape. In fact about $63 \%$ of the women agreed that a woman should submit to her husband's sexual demand irrespective of the inconveniences to her. The consensus from the qualitative instruments we used is that there is nothing like "marital rape" in a marriage because the woman is married to satisfy the man's urge in Benue State of Nigeria. About four out of every ten of the rape victims said it was the first time they had sexual experience.

\section{Health consequences}

International focus on domestic violence is due to its social and health consequences. In this study we asked respondents to indicate whether they have experienced some identified health problems normally associated with battery and/or rape. To measure the current experience of the health problems, we asked the respondents whether they have experienced these problems in the preceding two years to the study. Women who have experienced physical assault reported having lower abdominal pain (40.3\%), foul vaginal discharges (40\%), itching in the private parts (39\%), painful urination (I8.4\%), genital ulcer (35.7\%), bodily injury (31\%), miscarriage (29\%), unplanned pregnancy (30\%). Current experience of these health problems is not lower than 10 percent in each case.

The commonest mental health problems reported by the women who have experienced intimate partner violence include repeated headache (73\%), anxiety (57\%), menstrual prob- 
lems (37\%), insomnia (4I\%), depression $(67 \%)$, suicidal attempts (19\%), high blood pressure $(25 \%)$ and other health problems $(35 \%)$. The differences in the reporting of these health problems are significant between abused and non-abused women. The findings tally with similar studies elsewhere Jewkes et al. 2003; Arkutu 1995; Heise et al. 1994a). (Table not included).

Socio-demographic characteristics and forms of gender-based violence

Figures I-3 highlight the socio-eco- nomic patterns of the forms of genderbased violence identified in this area of study. Lifetime physical assault occurred more on women in the rural area, with no level of education, in farming and trading occupational groups, and those whose spouses have a low level of education. Psychological abuse occurred more to urban women, those with primary level of education. The same pattern obtains for women who reported forced sexual intercourse. The prevalence levels cut across the various socio-economic groups.

Fig. 1: Prevalence of gender-based violence by respondents level of education, Tivland, Nigeria

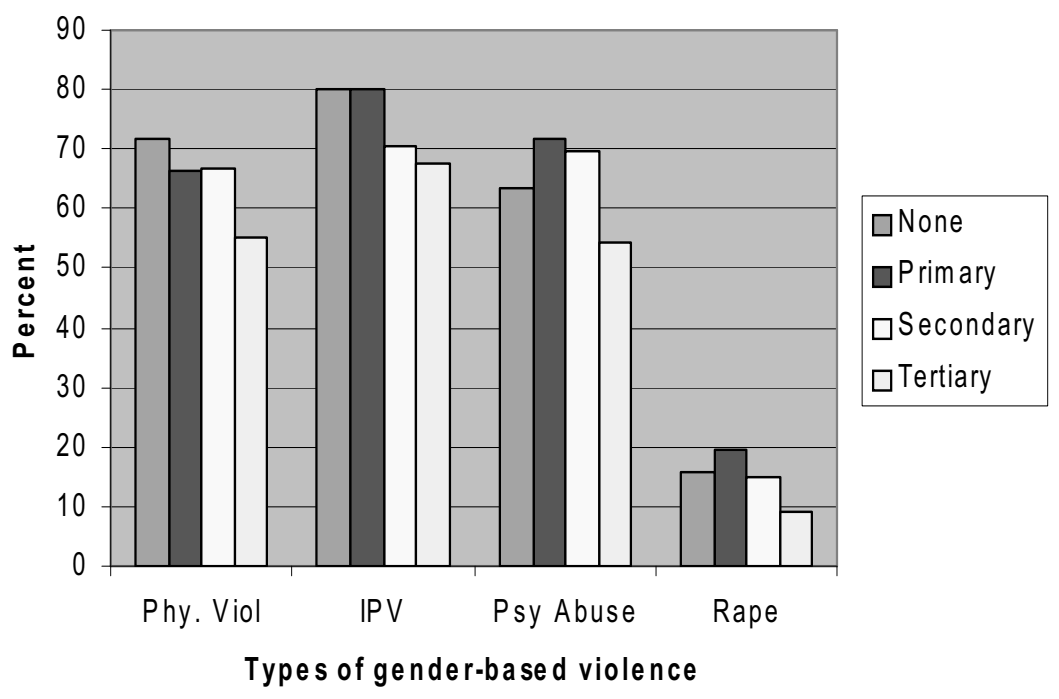




\section{Fig. 2: Prevalence of types of gender-based violence by occupational categories, Tivland, $\mathrm{N}$ ig eria}

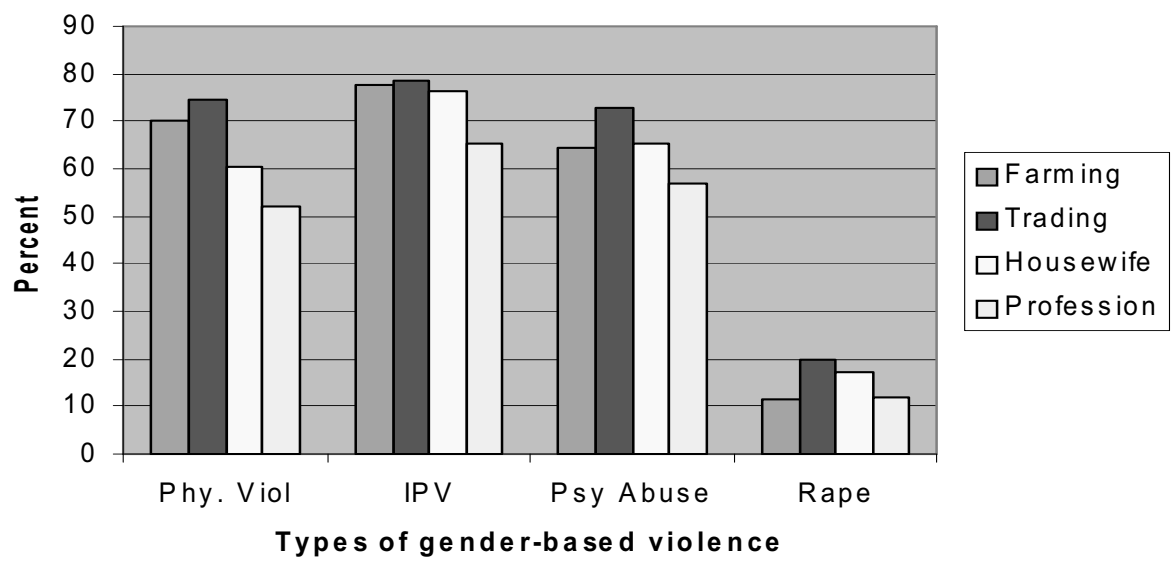

Predictors of forms of physical violence

\section{Lifetime physical violence}

Only three variables are significant predictors of lifetime experience of physical violence. These are current age, marital duration and gender role ideology. As age of a respondent increases, odd of experiencing lifetime physical violence relative to the younger age respondents decreases by 6 percent. This is true because the tendency to engage in physical assault by the victimizers would have decreased. The marital duration is the effect of longer term exposure, as the longer the women are exposed to violent environment, the more likely they are to experience lifetime violence. Those women who subscribe to gender role ideology, that is, that men are better than women in all respects and therefore should occupy primary place of authority and power in the society, are more likely to experience lifetime physical violence. It should be noted that the effect of place of residence, level of education, occupation are in the expected direction, though not significant. Women living in the urban areas of Benue State, Nigeria, are more likely to have experienced lifetime physical violence than those in the rural areas. Similarly, those with lower level of education are more likely to have experienced lifetime physical violence than otherwise.

\section{Lifetime intimate partner violence}

The pattern of the relationships remain the same even in the case of intimate partner violence, except with the additional effect of family size which shows that as family size increases, the odds of experiencing intimate partner violence decreases by 5 percent. This may be a result of the influence of age and the likelihood that such couples would have 


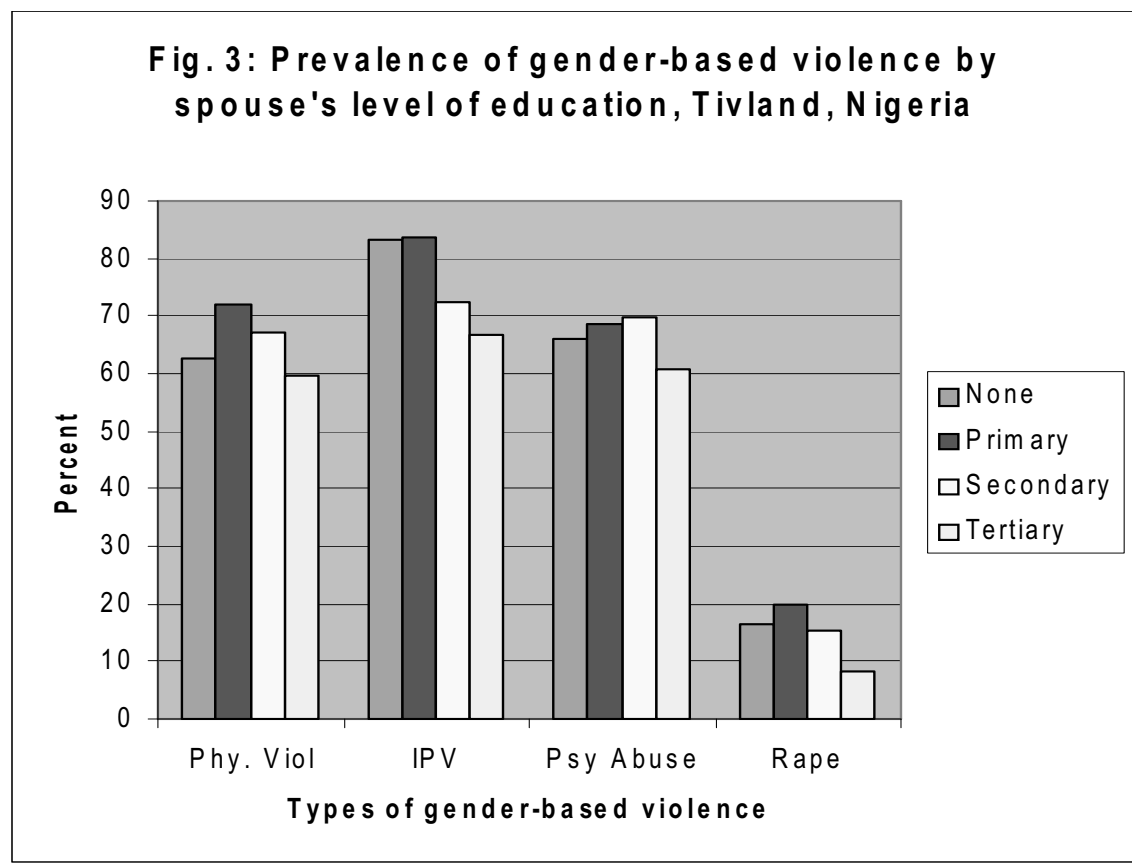

Keys: Phy viol = physical violence; IPV = intimate partner violence; Psy abuse $=$ psychological abuse

devised a self-corrective mechanism to correct any conflict arising in the marital union instead of engaging in a physical combat to resolve differences. Comparatively it has bee found that urban residence; education and types of marital union are key predictors of wife battery among the lgbos of Nigeria. In this same study while women's education was not statistically significant, that of the spouse was (Okemgbo et al. 2003). But in the Tiv study respondents' and partners level of education are insignificant.

Forced sexual intercourse (rape)

Urban women are more likely to report experience of forced sexual intercourse than rural women; women with lower level of education are more likely to have experienced forced sexual intercourse. Similarly women of the Catholic religious faith, those whose spouses have lower level of education, those engaged in farming and trading and those who have had lifetime physical violence are more likely to have been forced to have forced sexual intercourse. Belief in gender role ideologies impacts significantly on rape experience as those women who hold gender stereotypes are more likely to report experience of rape. In a similar study in the south-eastern part of Nigeria, Okemgbo et al. found that urban, monogamous, high educational level women and those with spouses who have high level of education are less likely to have suffered rape. 
Psychological abuse

The significant predictors of psychological abuse include age of respondents, marital duration and intimate partner violence. The effect of education and occupational categories are in the expected direction but not statistically significant. The lower the level of education, the less likelihood of psychological abuse. Among the Tiv of Nigeria, while the less educated women experience physical violence, the more educated ones experience psychological abuse. Gender beliefs are statistically significant. Those women who have had intimate partner violence or are still experiencing it are 15.5 times more likely to have experienced psychological abuse.

\section{Current intimate partner violence}

Those experiencing intimate partner violence are more likely to be from urban areas, have lower levels of education, catholic religion and trading occupation. In terms of the gender ideological beliefs, women who believe in gender inequality are more likely to be abused than otherwise. The relationship again brings to the fore the effect of gender role ideology on gender-based violence

\section{Conclusion}

The purpose of this study is to initiate changes in societal attitudes to issues of violence against women in Tiv ethnic group of Benue State, Nigeria. Entrenched norms and attitudes have made the practice of violence against women an accepted cultural practice in the area. The focus group discussions, in-depth interviews and the quantitative data have shown that the reported 25 percent prevalence of violent acts against women in the area is an underestimation (OAU, 1998). There is a high prevalence of violence against women in terms of wife battery and sexual rape. According to one female key informant and from the various female focus group discussions,

"There are various punishments they (men) give to us ... they beat us ... deny us sex ... there is no Tiv man that does not beat his wife ..."

Violence against women in Tivland takes various forms. Marital negligence is common and arises when the male partner refuses to take family responsibility because he wants to discipline the female partner. This takes many forms. According to the women in one of the focus group discussions:

"They (men) will refuse to buy you cloth. Or dig our farms for us or stop carrying out family responsibilities such as paying children's school fees".

Among the Tivs of Benue State, Nigeria, women do not have ownership of land, which clearly disempowers them and makes them subject to the whims and caprices of the men since the state is predominantly a farming community. In both urban and rural focus group discussions for women, it was a consensus of opinion that

"Here lands belong to our men.

What we owe is only the crop planted. If he tells you not to farm, you will not farm ..."

The family authority structure favors the men who take the major decisions affecting the household without reference to the woman. In situations where a woman is more 
influential, the husband will be derided.

Sexual rape is high. Our respondents acknowledged that having sexual intercourse with a young unmarried woman or another man's wife is rape but denied the existence of forceful sexual intercourse (sexual rape) in marriage. Focus group participants commented thus,

"We can say they force us to have sex when we are tired because of farm activities and household chores. If we refuse they beat us or may go out to other women. So to avoid being beaten or abused we yield. We do not call it rape in the way we understand rape" (FGD, women, aged 30-39, urban and secondary education).

A key female informant said that there is nothing like rape in a marital dyad and no woman has any right to report her affair with her husband as a rape. The underlying reason for a woman to have sex without her willing consent is borne out of fear of being beaten, abused or threat of divorce. A middle-aged woman, 40-49, commented thus:

"A Tiv man doesn't show love to his wife; anytime he has sexual desire, he wants to make love without any protest from the wife. He does not care about the wife's feelings. He jumps on her and jump out. He does not care."

However, forced sexual intercourse is frowned at when the victim involved is a young girl and or another person's wife. Because of shame and stigma associated with rape ("a raped girl is given a bad name and becomes the point of discussion and in most cases it is difficult for her to be married. It also brings shame to the family"), the focus group discussants reported that

"When your daughter or sister is raped, you do not discuss it openly or go to challenge the rapist to avoid exposing her to ridicule, shame and disgrace. Then you have to advise your daughter to avoid any behavior that would expose her to further rape. You cannot take the rapist to court or police. Doing these is exposing your family and daughter to ridicule. The police will even make a mockery of you to prove that your daughter is ever a virgin and to prove that she is actually raped" (FGD, Women, 30-39 and 40-49, urban and educated).

To the women in our qualitative data the solution to rape activities is to teach young girls morals while none recommended any action against the perpetrators of rape. Any girl raped is deemed to be the cause while the rapist is hailed as hero. The mother of the victim is blamed too and accused of not training her daughter to behave well and, in fact,

"Your fellow women in the community and even your husband will blame you for the rape. It will be regarded as a failure on your part as the mother".

Attitude to violence against women is supportive as most respondents see the tradition of wife battery in the area as a demonstration of the husband's love for her. Although they frowned at the act of rape in the community For instance, rural women observed in a focus group discussion that 
"Beating of stubborn wives is normal and still common. Our men will never stop beating us because that is a traditional way of disciplining and correcting us" (rural, uneducated women FGD).

The educated women though agreeing that wife battery in this community is regarded as a way of discipline, strongly objected to the practice. They maintained that it is fear of male violence that has made women to regard violence against them as a way of life. To them, the practice of gender-based violence should be made a legal offence but asked to comment on how it should be implemented, they replied that

"Intimate partner violence is a private family affair which should not be made a public issue. It is only on extreme occasions we go to the Social Welfare Board for advice and settlement. We cannot take the father of our children to court or police, except if it involves life or threat to it. Moreover, doing so has implications for your natal family names and your future generations. You will be seen as the family whose women take their husbands to court or police."

Others perceive it as necessary to discipline an erring and stubborn wife. It is not clear how a stubborn wife is determined in the area, but a principal women's leader in the area told us that "infidelity (perceived or real), refusal to satisfy husband's sex urge and not cooking food for the husband when he wants and even a simple complaint against the woman by a family member" merit a woman being classified as stubborn and can lead to beating and other abuses. A common comment during the fieldwork from the respondents and other community members who got idea of the purpose of the study was "A Tiv man must beat his wife no matter what you (we) do." The men believe they spent a lot of money on their wives as bride price and as such have to discipline them by any manifestation of violent acts either physical or psychological.

\section{Policy and program implications}

The survey data, though from a subethnic group in Nigeria, validates opinions about the pervasiveness of genderbased violence in various communities. More than two-third of the surveyed women reported being physically violated by an adult member of the family and most often the male members of the household (the father, the male friends and partner) and one-fifth reported having being raped and most of this occurred at a younger age of 15 , and 6 percent reported experiencing rape in the preceding twelve months to the survey. This confirms previous studies that most rape victims are adolescents. In fact about 19 percent of the adolescents in the area reported being raped.

It is unclear from the study why there is not much significant difference in prevalence rates among women of different socioeconomic backgrounds. Further studies are needed to clarify this finding, perhaps drawing data from different ethnic groups with diverse socioeconomic backgrounds. It is important to find out whether differences exist in gender-based violence among women of diverse ethnic and socioeconomic backgrounds in Nigeria 
as earlier study has reported such significant effect among the lgbos of Eastern Nigeria (Okemgbo 200I; Okemgbo et al. 2002; Odimegwu and Okemgbo 2003).

The study also showed that women are at greater risk of partner violence or rape irrespective of timeframe (lifetime or current). Moreover women who have suffered intimate partner violence are more significantly likely to be raped and psychologically abused. Given these positions, intimate partner violence should be considered a serious offence against women. In the geopolitical group where this study falls into, domestic violence is not regarded as a criminal offence and hence not punishable in the court of law. Violence against women in this area is committed by male partners in the homes as threefourth of the women battered were by their male partners, and $43 \%$ reported that their partners have insisted on sexual intercourse against their will. Given this finding, intervention strategies or activities should focus on the risks posed to women by current and former partners and members of the household.

Improving women's sexual and reproductive health has been a key objective of all governments after the International Conference on Population and Development (ICPD) in Cairo 1994. Gender-based violence impacts on all the most serious sexual and reproductive health problems facing women as this study has also shown. If these health problems are to be effectively addressed and, in particular, the tide of the HIV epidemic reversed, every government must commit itself to effectively combating gender-based violence. The health consequences of gender-based violence found by this study suggest that it is important that medical care providers receive information about the physical consequences of gender-based violence and the medical needs of the victims and appropriate treatment strategies. The need exists to integrate gender-based violence into national health programs. The social welfare unit should be strengthened and empowered to provide services to couples in conflict and victims of gender-based violence.

However further studies are needed to examine the health and socioeconomic consequences of genderbased violence involving a multidisciplinary research design. This multidisciplinary study will investigate the types of injuries sustained by assaulted women, medical services utilized and cost of such violence and services. More research is needed to determine how much of the findings can be explained by the respondents' willingness to report information to interviewers and how much by social, demographic and economic factors.

In terms of program intervention, strategies to combat domestic violence must attack the root causes of the problem in addition to treating the symptoms. This means challenging the social attitudes and beliefs that perpetuate male violence. This must confront the underlying cultural beliefs and social structures that perpetuate it. For instance the belief that partner violence is an act of love and discipline irrespective of its reproductive health consequence should be addressed. Laws that interfere with the ability of women to escape violent relationships should be 
identified and amended. More importantly community attitude to gender violence should be changed through a concerted information, education and communication programs. The various sections of the Tiv community need to be educated on the dangers of genderbased violence. Though Tiv women in the area organize themselves into groups for various socio-cultural activities they do not seem to be addressing the problem of gender-based violence. They are divided over the issue of violence. While some see it as a necessity to discipline a stubborn wife, others (the young ones) frown at it.

In terms of research, researchers should begin to question aspects of traditional culture that demean and degrade the status of women. The practice of marital rape - whether accepted or not, in any culture, is one of such issues. The inability of women to negotiate for safer sex in this period of HIV/AIDS gives an added danger to their health. The fact that the women believe strongly in gender stereotypes should form the focus of intervention programs in addressing the issue of gender violence. For as long as women still believe that men are better, stronger and more intelligent and logical, so long they will continue to be abused. Acceptance or rejection of the practice of partner abuse is a matter of the mind. Education that will highlight the health consequences of violence against women will be the best approach.

There are few studies addressing the issue of domestic violence in Nigeria. This area of research should be further explored. Nigeria is a multi-ethnic country with various educational levels, religions, cultures, beliefs and practices, which shape behavior. Research into gender-based violence must take cognizant of this fact so that ethnic-specific findings and programs should be designed. For instance while western influence has permeated the lifestyles of the southern regions of Nigeria, it is not so in the northern regions and that could be responsible for the lack of association between empowerment variables and genderbased violence. Multidisciplinary research design is a suggested approach.

\section{References}

Afkami, M; Greta Hoffman Nemroff and $H$. Vaziri (1998): Safe and Secure: Eliminating Violence against women and girls in Muslim Societies. Sisterhood International, Canada/ USA.

Albert, O.I. (1994): "Violence in Metropolitan Kano: A Historical Perspective", in Urban Violence in Africa: Pilot Studies, edited by Eghosa G. Osaghae et al. (1994). IFRA, Ibadan, Nigeria.

Arkutu, A.A. (1995): Health of Women, Health of Mothers: An Information Guide. Family Care International Inc, New York.

Beijing Platform (1995): Beijing Declaration and Platform for Action: Fourth World Conference on Women, Beijing, China, 4-I5 September, 1995.

Benue State of Nigeria (1996): Penal Code Law Cap 89 Laws of Northern Nigeria 1969. Ministry of Justice, Makurdi, Nigeria.

Blanc, A.B, Wolf, B, Gage, A.J et al. (1996): "Negotiating Reproductive Outcomes in Uganda", Calverton, Maryland: Macro International Inc. 
and Institute of Statistics and Applied Economics, Uganda.

Carrillo, Roxanna (1992): Battered Dreams. New York: UNIFEM

Coker, A.L and D.L. Richter (1998): "Violence against women in Sierra Leone: Frequency and Correlates of Intimate Partner Violence and Forced Sexual Intercourse", African Journal of Reproductive Health, Vol. $2(I): 6 I-72$.

Connors, J. F. (1989): Violence against women in the family. New York: United Nations

Haj-Yahia (2000): "Wife abuse and battering in the socio-cultural context of Arab society", Family Process 39:237-255.

Heise, L, J. Pitanguy and A. Germain (1994a): "Violence against women: the hidden health problem", World Bank Discussion Pattern No 255, Washington DC: The World Bank .

Heise, L.L., A. Raikes, C.H. Watts and A.B. Zwi (1994b): Violence against women: A neglected public health issue in less developed countries", Social Science and Medicine 39 (9): II65-II 79.

Hoffman, K., D.H. Demo and J.N. Edwards (1994): "Physical wife abuse in a non-Western society: an integrated theoretical approach", Journal of Marriage and the Family 56: |3|-| 46.

Jewkes, R.K., J.B. Levin, L.A. Pennkekana (2003): "Gender inequalities, intimate partner violence and HIV preventive practices: findings of a South African Cross-Sectional study", Social Science and Medicine 56: I25-I34.

Kisseka, Mere and B. Otesanya (1988):

"Sexually transmitted diseases as a gender issue: examples from Nigeria and Uganda", Paper presented at AFARD/AAWORD $3^{\text {rd }}$ General Assembly on the African Crises and the Women's Vision of the way out. Dakar, Senegal, August.

Kim, K and Cho, Y (1992): "Epidemiological survey of spousal abuse in Korea", Intimate Violence: Interdisciplinary Perspectives. Washington, Hemisphere Publishing Corp.

Koenig, MA., Hossan, M.B. S. Ahmed and J .Haagar (1999): "Individual and community-level determinants of domestic violence in Rural Bangladesh", Working Paper Series, Johns Hopkins School of Public Health, Baltimore.

Koenig, MA., T. Lutalo, F. Zhao et al. (2003): "Domestic violence in rural Uganda: evidence from a community-based study", Bulletin of the World Health Organization 81:5360.

OAU (1998): Baseline survey on Harmful Traditional Practices in Nigeria. Report to UNDP, Lagos.

Odimegwu, C.O (1998): "Communitybased study on girl-child status among the Igbo of South East Nigeria", Final Report to IACNigeria.

Odimegwu, C.O (2000): "VAW Prevention Initiatives: Changing Societal attitudes to violence against women", Research Report submitted to J.D. and C.T. MacArthur Foundation Fund for Leadership Development Program, Nigeria.

Odimegwu, C.O. and C.N. Okemgbo (2003): Gender role ideologies and prevalence of domestic violence in South East Nigeria", The 
Anthropologist ,(forthcoming).

Odunjirin, O. (1993): "Wife battering in Nigeria", International Journal of Gynecology and Obstetrics 4I (I59): 164.

Okemgbo, C.N (2001): “ Correlates of domestic violence in South-East Nigeria", M.Sc Dissertation held by the Dept of Demography and Social Statistics, Obafemi Awolowo University, lle-Ife, Nigeria.

Okemgbo, C.N., Omideyi, A.K. and C.O. Odimegwu (2002): "Prevalence, Patterns and Correlates of Domestic Violence in Selected Igbo Communities of Imo State, Nigeria", African Journal of Reproductive Health Vol 6 (2): I0I108.

Raikes, Alanagh (1990): "Pregnancy, Birthing and Family Planning in Kenya: Changing Patterns of
Behavior: A Health Utilization study in Kissi District". Copenhagen: Center for Development Research. Sogbetun, A.O and K.O. Osoba (1977): "Sexually transmitted diseases in Ibadan, Nigeria", British Journal of Veneral Diseases 53: 158.

Tseror, Timothy (1992): Tiv and their Neighbours. PLHA Press.

\section{Acknowledgement}

The John D. and Catherine T. Macarthur Foundation Fund financially supported this study for Leadership Development in Nigeria under Grant No. 98-55983-000. We appreciate this gesture. We also express our thanks to all the women and community leaders who helped in making this study a huge success. 